\title{
An evaluation of the activity of biologically synthesized silver nanoparticles against bacteria, fungi and mammalian cell lines.
}

\author{
Tabeer Khan ${ }^{1,2,3}$, Azra Yasmin ${ }^{1,2} *$ and Helen E. Townley ${ }^{3}$ \\ ${ }^{1}$ Microbiology and Biotechnology Research Lab, Fatima Jinnah Women University, Department \\ of Environmental Sciences, Rawalpindi, Pakistan. \\ ${ }^{2}$ Department of Biotechnology, Fatima Jinnah Women University, Rawalpindi, Pakistan. \\ ${ }^{3}$ University of Oxford, Nuffield Department of Obstetrics and Gynaecology, Oxford, UK \\ Corresponding email: azrayasmin@fjwu.edu.pk \\ Contact: +923214079956
}

Tabeer Khan

E-mail address:tabeerkh@gmail.com

Azra Yasmin*

E-mail address: azrayasmin@ fjwu.edu.pk

Helen Townley

E-mail address: helen.townley@obs-gyn.ox.ac.uk

\section{Acknowledgements}

This study was partly supported by International Research Support Initiative Program, Higher education commission of Pakistan. Authors are thankful to Dr. Waqar Mahmood (Department of Physics Fatima Jinnah Women University) for reviewing the EDX results and Dr. Anila Fariq for the statistical analysis. 


\begin{abstract}
Biogenic silver nanoparticles due to their size, surface characteristics and strong antimicrobial properties are getting much attention for various applications. The present study aimed to investigate the synthesis of silver nanoparticles from the indigenous strain Bacillus sp. MB353 (PRJNA357966). Detailed characterization of silver nanoparticles was performed by UV-Vis Spectrophotometer, FTIR, SEM and XRD. Biogenic silver nanoparticles were crystalline with average size 49-53 nm. These silver nanoparticles possessed good antibacterial activity against Gram positive and Gram negative bacteria (E. coli, Bacillus subtilis, Staphylococcus aureus, Klebsiella pneumoniae, Enterococcus faecium, Enterococcus faecalis and Streptomyces laurentii). The nanoparticles showed excellent antifungal activity against Aspergillus niger, Aspergillus fumigatus, Fusarium soleni. Occurrence of negligible antioxidant activity pointed out the possible mode of antimicrobial activity in generation of reactive oxygen species and interaction of silver ions with bacterial cells. Incubation of silver nanoparticles with mammalian cell lines (Rhabdomyosarcomas) and fibroblast cells showed cell death and inhibition of proliferation. Possible mode of cytotoxicity was due to changes in ROS generation and intracellular calcium levels. These findings suggested that biogenic silver nanoparticles could be used as alternative agents for biomedical purposes such as antibacterial and antifungal agents. Similarly they could only be used as anticancer agents if applied in site-directed therapies as they inhibited proliferation of cells and induced apoptosis by generation of ROS with no ATP production required for cellular energy.
\end{abstract}

\title{
Key Words
}

Nanobiotechnology, Bacillus sp, Silver nanoparticles, Cancer cell lines, Antimicrobial activity

\section{Introduction}

Antibiotic resistance among human pathogens is a big challenge in the fields like pharmaceutical and biomedicine. Therefore to enhance the efficiency of drugs and development of new alternative methods of treatment, nanoparticles seems to have a high potential to solve the problem. Similarly cancer is the leading cause of death worldwide with limited treatment methods available. There is 
need for alternative treatment strategies to treat cancer cells and to combat multidrug resistant microorganisms $[1,2,3]$.

Consequently, current focus has shifted towards more environmentally friendly methods for nanomaterial synthesis. Nanda and co-workers, for example, have synthesized silver nanoparticles using Staphylococcus aureus, and the particles were shown to possess effective activity against methicillin-resistant Staphylococcus aureus, methicillin-resistant Staphylococcus epidermidis and Streptococcus pyogenes [4]. Microbial methods of nanoparticle synthesis may take place extracellularly or intracellularly. The extracellular process is easiest since intracellular synthesis requires further treatments to release the nanoparticles from the cells [5].

In Pakistan, the numbers of clinical infections caused by Enterococcal and Staphylococcal species are consistently increasing and are considered a serious threat due to their intrinsic resistance against many commonly used antibiotics which may lead to therapeutic failures [6,7]. Effective antimicrobial activity of silver nanoparticles has been reported against Escherichia coli [8,9]. Moreover, to enhance the effectiveness and reduce the resistance of antibiotics/AgNPs, nanoparticles can be used as conjugants with different antibiotics [10,11]. Some reports suggested that certain bacteria possess resistance against silver but exact mechanism of resistance is not fully known. Also bacteria don't develop resistance against silver as compared to antibiotics because silver nanoparticles can interact simultaneously with multiple targets in the microbial cell. Silver nanoparticles synthesized from Bacillus safensis LAU 13 have proved to be effective against $E$. coli, $S$. aureus, $P$. aeruginosa and $K$. granulomatis. Resistance of these nanoparticles was found to get improved by ofloxacin, augmentin and cefixime [12]. In addition to bacterial control, nano-silver may have applications in controlling fungal diseases. Fungal infection is a major concern in crops, and excessive use of pesticides can cause environmental and health issues [13]. Biologically synthesized silver nanoparticles have previously been reported to have good antifungal activity against a variety of pathogens [14].

There is scarcity of research regarding invitro toxicity and exact mechanism of cytotoxicity of silver nanoparticles. Safety concerns, however, require evaluation of the toxicity of silver nanoparticles since such particles could penetrate in organs after entering the bloodstream, and could affect the blood brain barrier and become neurotoxic or genotoxic $[15,16]$. 
The present study focuses on the biological synthesis of silver nanoparticles by using nonpathogenic environmental strain Bacillus sp. (MB353). In addition, the effect of $\mathrm{pH}$ and temperature on AgNPs production was studied using 'Expert design' software. Response surface methodology was applied to optimize production of silver nanoparticles. The nanoparticles were characterized and their antimicrobial potential assessed against some multidrug resistant pathogens common in Pakistan. Variance was calculated by 2 way ANOVA in Excel. Subsequently for the first time the cytotoxicity of silver nanoparticles was assessed against Human Rhabdomyosarcoma cells and control fibroblast cells. Possible mechanisms of cytotoxicity were also evaluated.

\section{Methodology}

Bacterial strain MB353 (Bacillus sp.) was isolated from the industrial effluents of Hattar Industrial estate. The bacterial strain was purified, characterised and identified at the Microbiology and Biotechnology Research lab, Fatima Jinnah Women University, Rawalpindi, Pakistan.

Bacillus sp. (MB353) was used for the synthesis of nanoparticles following standard protocol with slight modifications [17]. Appearance of dark brown colour indicated the presence of silver nanoparticles.

\section{Characterization of synthesized silver nanoparticles}

The coloured supernatant was analyzed by UV-visible Spectrophotometer (Shimadzu UV 1602) and a full scan from 300-700 was recorded. Silver nanoparticles showed absorption maxima at 410-430nm.

\section{FTIR and XRD Analysis}

To identify the functional groups of the synthesised silver nanoparticles, FTIR spectroscopy (FTR8400, Shimadzu, Japan) was performed. Bacterially synthesized silver nanoparticles were dried overnight and mixed with analytical grade $\mathrm{KBr}$ to prepare the pellets. Pellets were scanned from $400-4000 \mathrm{~cm}^{-1}$. Silver nanoparticles structure was further predicted by X-ray diffraction (XRD). Origin Pro software was used to analyze XRD data and calculate the crystallite size.

\section{Scanning Electron Microscopy and EDX and Zeta potential}

The size and morphology of the biologically synthesised silver nanoparticles was analyzed by Tescan Field Emission Scanning Electron Microscope (FESEM) at Institute of Space Technology, 
Islamabad. Images were taken by drop coating of silver nanoparticles over carbon coater grid and analyzed by FESEM. Energy dispersive X-ray analysis was also recorded.

\section{Antimicrobial effect of AgNPs}

The microbial synthesized silver nanoparticles were tested for their potential antimicrobial activity against different bacteria (Escherichia coli, Bacillus subtilis, Staphylococcus aureus, Klebsiella pneumoniae, Enterococcus faecium, Enterococcus faecalis and Streptomyces laurentii) and fungal pathogens (Aspergillus niger, Aspergillus fumigatus, Fusarium soleni, Mucor sp.). Quantitative measurement of antimicrobial activity of MB353AgNPs was assessed. All the bacterial pathogens were inoculated in nutrient broth and AgNPs concentrations 1, 5, 10, 15, 20 and $25 \mu \mathrm{g} / \mathrm{ml}$ were added. Bacterial pathogens were incubated at $37^{\circ} \mathrm{C}$ [17].

Fungal pathogens were grown in Potato Dextrose Broth (PDB) and NPs were tested at concentrations of 10 and $50 \mu \mathrm{g} / \mathrm{ml}$. A macro dilution method with slight modifications was used for antifungal activity assessment [18]. Control tubes contained pathogens without nanoparticles. Fluconazole $(10 \mu \mathrm{g} / \mathrm{ml})$ was used as a positive control. All tubes containing fungal pathogens, and control tubes, were incubated statically at $30^{\circ} \mathrm{C}$. After 24 hours of incubation, growth was measured at $600 \mathrm{~nm}$ using a UV-visible Spectrophotometer. Experiments were performed in triplicate.

\section{Antioxidant activity of biologically synthesized silver nanoparticles}

For antioxidant analysis, DPPH scavenging activity was performed [19]. Different concentrations of silver nanoparticles $(0.1,0.5,1,5,10,15 \mu \mathrm{g} / \mathrm{ml})$ were prepared. The reaction mixture was prepared following protocol. Absorbance was recorded after incubation time by UV-visible spectrophotometer at $517 \mathrm{~nm}$. Percentage of inhibition was calculated by following equation.

Percentage of inhibition $=\underline{\text { Control Absorbance-Sample absorbance }} \times 100$

\section{Control Absorbance}

\section{Cell culture and treatment}


Human Rhabdomyosarcoma cells (RD [ATCC code CCL-136] and RH30 [ATCC code CRL7763]) and Human fibroblast cells were used to test the silver nanoparticles. Cells were cultured in Dulbecco's modified Eagle's medium (DMEM), supplemented with 10\% fetal bovine serum (FBS), $100 \mathrm{U} / \mathrm{ml}$ penicillin (Sigma-Aldrich), $0.1 \mathrm{mg} / \mathrm{ml}$ streptomycin (Sigma-Aldrich) and 2mM L-Glutamine at $37 \circ \mathrm{C}$ in a $5 \% \mathrm{CO}_{2}$ incubator. The cells were cultured in 96-well plates at a density of $1 \times 10^{4}$ cells per well. Cells were passaged every 3 to 4 days. In all experiments, the samples were in triplicates and each experiment was repeated twice. The untreated cells were considered as the control.

\section{Cell viability test}

Viability of all three cell types (RD, RH30 and Fibroblast) was evaluated using the Crystal violet assay. Cells were seeded and after $24 \mathrm{~h}$, the cells were treated with various concentrations of Silver nanoparticles $(0,0.1,0.5,1,1.5,2,2.5,3,3.5,4,4.5,5,5.5,6,6.5,7,7.5,8,8.5,9,9.5,10$ and $10.5 \mu \mathrm{g} / \mathrm{mL}$ ) for 24 hours. After incubation cells were washed and treated with crystal violet following standard protocol [20]. Crystal violet stain was washed and $100 \mu 1$ of solubilizer (1\% SDS, $10 \%$ acetic acid) was added to dried plate. Then absorbance was recorded at 595nm (Tecan plate reader).

\section{Cell proliferation ability: Clonogenic Assay}

Cell proliferation was evaluated using the colony forming assay. Cells were incubated with the particles overnight. Cells were counted using a hemocytometer and triplicate 6 well plates were prepared with a seeding cell density of 750 cells per well. Plates were incubated for two weeks followed by crystal violet staining. Colonies were then counted manually.

\section{Reactive oxygen species analysis}

$\mathrm{RD}, \mathrm{RH} 30$, and fibroblast cells were seeded at $1 \times 10^{4}$ cells per well. Triplicates wells were prepared for each concentration of silver nanoparticles. Concentrations used were $0.1,0.5,1,4,7$ and $10 \mu \mathrm{g} / \mathrm{ml}$. Cells were incubated, after the incubation period nanoparticles were added to the cells and incubated again overnight. After 24 hours, cells were washed with PBS and then stained with the $100 \mu \mathrm{l}$ of $\sim 1.5 \mu \mathrm{M}$ (recommended range 1-10 $\mu \mathrm{M}$ ) 2',7'-dichlorodihydrofluorescein diacetate $\left(\mathrm{CMH}_{2} \mathrm{DCFDA}\right.$, Invitrogen) in PBS. Cells were then allowed to incubate for one hour for the dye to permeate the cells. Fluorescence was measured at Ex. $465 \mathrm{~nm}$ and Em. $510 \mathrm{~nm}$. 


\section{Intracellular Calcium level}

Cells were seeded as explained earlier. Growth medium was removed and cells were washed twice with PBS. Fluo-4-Am dye solution (stock solution of dye prepared in DMSO) was added, and cells were incubated for 1 hour. After that the dye was removed, washed with $0.1 \mu \mathrm{g} / \mathrm{ml}$ PBS and then 10 $\mu \mathrm{g} / \mathrm{ml}$ of AgNPs were added. PBS alone was used as reference. Fluorescence was recorded after 2, 4, 5, 6 and 20 hours, at Ex. 495nm Em. 519 nm.

\section{Results}

\section{Bacterial synthesis of silver nanoparticles}

Isolation of bacterium Bacillus sp. MB353 was carried out from effluent samples from Hattar industrial estate, Pakistan. The bacterium was Gram positive, rod shaped, and identified as Bacillus $s p$. by $16 \mathrm{~S}$-rRNA sequencing. This bacterial isolate was screened for the synthesis of silver nanoparticles. A nitrate reduction test confirmed the presence of enzyme nitrate reductase by the bright red color. The presence of nitrate reductase is key for silver nanoparticles synthesis. Physiological conditions such as $\mathrm{pH}$ and temperature were optimized for the bacterial isolate to synthesize silver nanoparticles. Bacillus sp. MB353 synthesized silver nanoparticles optimally at $45^{\circ} \mathrm{C}$ and acidic $\mathrm{pH}$ (Fig. 1).

In the supernatant containing silver nitrate, a change in color from yellow to dark brown occurred after 48 hours, which is probably due to the excitation of surface Plasmon resonance of silver nanoparticles. A UV-visible spectrum was obtained from 300-700 nm and a clear peak at 400nm was observed due to the presence of silver nanoparticles (Fig. 2b).

\section{Statistical Optimization of MB353AgNPs}

A central composite design under Response Surface Methodology (RSM) was employed using Design expert software to optimize a system from several responses and different types of experimental run. A two level factorial design was used to achieve all possible combinations of input variable that are able to optimize the response. A set of total 11 experiments were performed. Overall summary of descriptive statistics on factors used for synthesis of silver nanoparticles are given in table 1. According to the analysis of variance (ANOVA), the quadratic model was found to be significant at $p$ value less than 0.05 . Further a response surface plot is the graphical representation of the regression equation obtained from the established model, $\mathrm{X} 1$ represent $\mathrm{pH}$ 
variable and X2 for temperature. This surface plot showed the interaction among parameters and define the optimum temperature and $\mathrm{pH}$ for maximum yield of silver nanoparticles. Predicted optimum conditions for MB353, (as shown in interaction graph) were $\mathrm{pH} 7$ and temperature $35^{\circ} \mathrm{C}$ (Fig. 2).

\section{FTIR spectroscopic analysis}

FTIR analysis of MB353AgNPs showed prominent peaks at 34190.90, 2964.69 (O-H stretch), 2351.30, 1620.26 (C=O), 1454.38(C=C), 1384.91 $\left(\mathrm{CH}_{3}\right.$ bend $), 1319.35\left(\mathrm{NO}_{2}\right.$ stretch $), 1261.49(\mathrm{C}-$ $\mathrm{H}$ wag $\left(-\mathrm{CH}_{2} \mathrm{X}\right)$ alkyl halide), 1095.60 (C-O-C stretch), 1022.31 (C-OH stretch), 868.00 (C-H aromatic bending), 800.49 (C-H aromatics) (Fig. 3). Prominent peaks at 34190, 2964. 2351 and 1620 assigned to carboxylic acids, aldehydes and ketones which was remarkable indication of presence of hydroxyl and $\mathrm{C}=\mathrm{O}$ groups originated from amino acids that are coupled to the reduction of silver ions. Similarly, the major peaks corresponded to the presence of alcohol, phenols, amide groups, carboxylic acids, esters and ethers. Medium and narrow peaks were related to aromatics groups, $\mathrm{CH}_{3}$ and alkyl halides. These results predicted the presence of primary and secondary amines at the time of synthesis of silver nanoparticles. These amino acids suggested the presence of enzymes such as nitrate reductase around the nanoparticles that act as stabilizers and also as reducing agent.

\section{SEM and XRD analysis}

The size of the biologically synthesized silver nanoparticles was determined using Scanning Electron Microscopy, which was approximately 49-53nm (Fig. 4a). EDX spectra confirmed the presence of a silver ion peak at $3 \mathrm{Kv}$. Other than silver, nitrogen and oxygen were also present in the sample; which indicated that biological components such as proteins may be present as stabilizing agents (Figure 4b). To obtain further understanding of the stability of the biologically synthesized silver nanoparticles, Zeta potential was measured. Zeta potential of the silver nanoparticles was found to be $-18.36 \mathrm{mV}$, which makes them less stable in suspension form. XRD (X-Ray diffraction) analysis of biologically synthesized silver nanoparticles showed that they were crystalline in nature with most preferable orientation lies at $31.96^{\circ}, 38.28^{\circ}, 44.5^{\circ}$ and $64.82^{\circ}$ (20/degree) indexed as 111, 200, 220 and 311 plane of face centered cubic silver nanoparticles (Fig. 5). Crystalline size has been calculated by Debye Scherrer formula i.e. 


\section{$D=0.9 \lambda / \beta \operatorname{Cos} \theta$}

$\beta=1 / 2\left[2 \theta_{2}-2 \theta_{1}\right]$ which is full width at half maximum.

Calculated value of D from above mentioned equation was 15.13nm (MB353AgNPs). Since most of the nanoparticles have crystalline nature as verified in XRD analysis which also showed polycrystalline silver nanoparticles. Further dislocation density was calculated by following formula.

\section{Dislocation density $(P)=1 /(D)^{2}$}

With increase in angle $(\boldsymbol{\theta})$ intensity of crystals decreased and calculated dislocation density of MB353AgPs was $0.0043 \mathrm{~A}^{\mathrm{o}}$ which decreased as the crystallite size increased.

\section{DPPH Scavenging activity of silver nanoparticles}

Antioxidant activity was studied by examining the scavenging capacity of the 2, 2-diphenyl-1picrylhydrazyl (DPPH) free radical. DPPH scavenging activity of the silver nanoparticles synthesized from MB353 was negligible. There might be a possibility that silver nanoparticles were not involved in scavenging of oxygen radicals at all rather they trigger generation of reactive oxygen species (Fig. 6). Ascorbic acid (Vitamin C) concentrations $(0.1-15 \mu \mathrm{g} / \mathrm{ml})$ were used as reference because vitamin $\mathrm{C}$ is one of the best known antioxidants. The antioxidant activity of the silver nanoparticles was insignificant than that of ascorbic acid at $0.1-15 \mu \mathrm{g} / \mathrm{ml}$ NPs concentrations.

\section{Antibacterial Activity of silver nanoparticles}

Silver nanoparticles were tested for efficacy against E. coli and Klebsiella species due to their alarmingly high rate of drug resistance in Pakistan. Biogenic MB353AgNPs showed increasing efficacy of bacterial growth inhibition with increasing concentration. At a concentration of $25 \mu \mathrm{g} /$ $\mathrm{ml}$ silver nanoparticles were able to inhibit E.coli growth by $94 \pm 0.047 \%$ i.e. more effectively than $10 \mu \mathrm{g} / \mathrm{ml}$ Streptomycin (Fig. 7). Streptomycin $(10 \mu \mathrm{g} / \mathrm{ml})$ was not very effective at inhibiting the growth of $K$. pneumoniae $(42 \pm 0.01 \%)$ whereas $25 \mu \mathrm{g} / \mathrm{ml}$ silver nanoparticles showed inhibition of $63 \pm 0.035 \%$ (Fig. 6).

Staphylococcus aureus is another clinically important pathogen. In Pakistan and India methicillin resistant Staphylococcus aureus has been found in $42-51 \%$ of cases [21]. Efficacy of the silver 
nanoparticles against Staphylococcus aureus was weak (40 $\pm 0.001 \%)$, compared to Streptomycin, but may still be useful since bacteria are less likely to be able to develop resistance against nanoparticles. Enterococcus faecalis and Enterococcus faecium were tested next since they are clinically relevant, being present in $85-90 \%$ and of 5-10\% human infections, respectively [22]. Enterococci are able to colonize rapidly and cause infections including urinary tract infections, genital tract infections, and endocarditis, all with multidrug resistance patterns. The present study identified the potential of biogenic silver nanoparticles against Staphylococcus aureus, Enterococcus faecalis and Enterococcus faecium. In both Enterococcus species tested, streptomycin was quite effective, and although inhibition was not quite as effective using the MB353AgNPs, Enterococcus faecalis showed 76 $\pm 0.005 \%$ inhibition and Enterococcus faecium $67 \pm 0.04 \%$ (Fig. 7). Bacillus subtilis was investigated due to its high profile in food poisoning. The

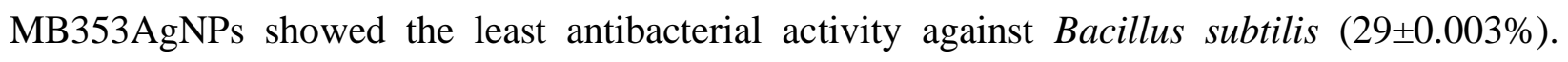
Conversely, Streptomyces species which may infect lesions and scratches and instigate abscesses [23], were the species in which MB353AgNPs showed the highest antibacterial activity with percentage inhibition of growth at almost $100 \pm 0.2 \%$ for $25 \mu \mathrm{g} / \mathrm{ml}$. These results showed that MB353AgNPs have potential to be used as an effective alternative weapon against bacterial pathogens.

\section{Antifungal activity of silver nanoparticles}

In addition to find new antibacterial agents, it is equally important to look at novel agents to combat fungal infections. The MB353AgNPs were tested against four species of fungi, and at two different concentrations (Fig. 8). The nanoparticles showed good activity against Aspergillus niger with $94 \pm 0.2 \%$ growth inhibition at $50 \mu \mathrm{g} / \mathrm{ml}$ nanoparticle concentrations. The antifungal activity of the silver nanoparticles against Aspergillus fumigatus was relatively lower $(60 \pm 1 \%)$ than that of Aspergillus niger (Fig. 8). Fusarium species was also tested due to its involvement in a number of plant, animals and human infections, and plant infections such as crown rot, head blight, and scab on cereal grains. The MB353AgNPs showed good activity against Fusarium soleni; $10 \mu \mathrm{g} / \mathrm{ml}$ NPs showed $55 \pm 1.1 \%$ growth inhibition, which increased to $74 \pm 1 \%$ at a concentration of $50 \mu \mathrm{g} / \mathrm{ml}$. In contrast, the antifungal activity of the silver nanoparticles against Mucor sp. was negligible at both concentrations of nanoparticles. This illustrates the importance of assessing the antifungal compound against the specific species to be treated. Commercial antifungal drug Fluconazole (10 
$\mu \mathrm{g} / \mathrm{ml}$ ) was used as control. This antifungal drug is excessively used as efficient antifungal against different fungal infections. To generate a comparison between commercial antifungal and silver nanoparticles antifungal activity fluconazole was used.

\section{Cytotoxicity Analysis against mammalian cells}

The MB353AgNPs were also tested against immortalized mammalian cell lines. Cytotoxicity was evaluated in two Human Rhabdomyosarcoma cancer cell lines (RD and RH30) (Fig. 9). The effect of the nanoparticles on healthy cells was also assessed using normal fibroblast cells. It can be seen that there is a pivot point where toxicity is significantly increased above $5 \mu \mathrm{g} / \mathrm{ml}$, above this concentration the nanoparticles are not biocompatible. There is increased cell death recorded above this concentration in fibroblast cells. The RD cancer cell line was not affected by MB353AgNPs in a way that would not be useful for anticancer therapy. In general, the control fibroblast cells showed greater cell death, which is the inverse situation of an ideal therapy. RH30 cells responded in a slightly better way than RD cells to the MB353AgNPs, but cell death was still greater in control fibroblast cells.

\section{Cell Proliferation of mammalian cells}

Cytotoxicity shows cell death after a short incubation period, however, a colony forming assay (CFA) can show the effect on surviving cells to proliferate over several generations. Cell proliferation was assessed after treatment with nanoparticles at four different concentrations (Fig. 10). The control fibroblast cells were the most sensitive towards the silver nanoparticles and the CFA (Colony formation assay) confirmed that their cell cycle progression was effected. Up to a concentration of $0.5 \mu \mathrm{g} / \mathrm{ml} \mathrm{MB} 353 \mathrm{AgNPs}$, the decrease in colonies was similar for RD and RH30

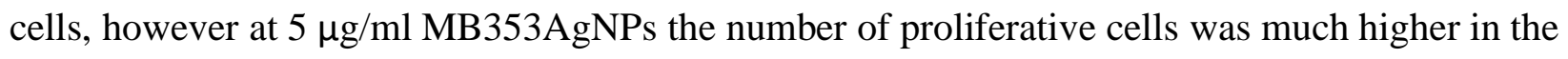
RMS cells than the fibroblasts. These results are consistent with those of the cytotoxicity assay. Since the silver nanoparticles appear to be more toxic to normal fibroblast cells than the RMS cells this would not be a good therapy unless the particles were targeted only to the tumor cells. Of course it is possible that other cancer cell lines may respond differently.

\section{Reactive Oxygen Species induction in mammalian cells}

Nanosilver cytotoxicity has been linked membrane damage can result in increased production of reactive oxygen species (ROS), and an increase in intracellular calcium ions, which further causes 
organelle damage leading to apoptosis [24]. ROS generation of MB353AgNPs were assessed at $0.1,0.5,1,4,7,10 \mu \mathrm{g} / \mathrm{ml}$, and fluorescence was measured after 2, 4 and 6 and 20 hours (Fig. 11). RH30 cells showed the highest initial levels of ROS overall (Fig. 11b). The highest level was $113.46 \pm 0.8 \%$ after 2 hours of interaction with $7 \mu \mathrm{g} / \mathrm{ml}$ silver nanoparticles. However, ROS levels fell over the incubation period and remained stable between 6 hours and 20 hours. In general, longer incubation times showed reduced levels of ROS indicating either greater cell death, or cessation of the ROS due to a completed stress response within the cells. RD cells showed a spike in ROS after 4 hours, followed by a slow return to original levels (Fig. 11a). Incubation with higher concentrations of MB353AgNPs showed the highest levels of ROS. Fibroblast cells showed less of a decrease in ROS over the first 4-6 hours than RH30 cells, but subsequently increased to levels greater than those after 2 hours for all concentrations of nanoparticles. This may be related to the change in the number of living cells since there is a marked increase in cell death after 5 hours incubation with MB353AgNPs (Fig. 11c). Thus, it appears from the data that there is a broad relationship between ROS generation and cell death. This would imply that ROS generation as a consequence of exposure to MB353AgNPs is involved in cellular toxicity.

\section{Intracellular Calcium Level}

Intracellular calcium level was assessed in RMS and fibroblast cells. Concentrations of MB353AgNPs used for the analysis were 0.1 and $10 \mu \mathrm{g} / \mathrm{ml}$. Comparison of the ROS spike in RD cells (Fig. 11a) and the calcium spike (Fig.12a) shows that both occur around 4 hours, indicating a probable link. However, it is not possible from this data to determine whether one transient initiates the other. RH30 cells showed an initial decrease in calcium levels followed by an increase over the period between 6 and 20 hours (Fig. 12b). The fibroblast cells also showed an initial decrease in calcium levels followed by recovery at 6 hours and a stable level to 20 hours (Fig. 12c). The return to $100 \%$ by 6 hours which is not seen in the RMS cell lines, may indicate why fibroblast cells show the lowest cell death, given that calcium is involved in cell death signaling cascade.

\section{Discussion}

Present study aimed to synthesize silver nanoparticles from Bacillus sp. MB353 isolated in Pakistan. Synthesized silver nanoparticles were obtained; indicated by change of colour in the bacterial supernatant from a pale yellow to dark brown. (Fig. 2a). Such a colour change can be due 
to the oscillation of silver ions and surface plasmon resonance. Similar observations were noted during the extracellular synthesis of silver nanoparticles from the fungus Aspergillus fumigatus [25]. The UV visible spectrophotometer characterization confirmed the synthesis of silver nanoparticle from Bacillus sp. The synthesized silver nanoparticles gave a maximum absorption, in the strong and broad peak, at $420 \mathrm{~nm}$ (Fig. 2b). A similar peak has been observed in a number of other studies and was assigned as surface plasmon resonance [26]. FTIR analysis gave further insights into the possible reduction mechanism that might be involved in the reduction and stabilization of silver nanoparticles. FTIR data showed several peaks corresponded to alcohol, phenols, amide groups, carboxylic acids, esters and ethers indicating presence of enzymes/proteins probably nitrate reductases as reducing and stabilizing agents.

Predominant peaks $3423.76 \mathrm{~cm}^{-1}, 1626.05$ and 1093.67 were assigned to stretching and bending vibrations of amines which confirmed that bacterial culture contain active proteins that aided in AgNPs synthesis and stabilization (Fig. 3) and was also confirmed by previous studies [26]. These proteins were found to bind with nanoparticles either through free amine groups or via cysteine residues [27].

It is considered that Zeta potential positives values greater than $+30 \mathrm{mV}$ or negative values greater than $-30 \mathrm{mV}$ are stable [25]. In XRD four peaks at $2 \theta$ values of $31.96^{\circ}, 38.28^{\circ}, 44.5^{\circ}$ and $64.82^{\circ}$ (20/degree) indexed as 111, 200, 220 and 311 identified to be due to silver metal, where as some other $2 \theta$ peaks of non-reduced silver nitrate was also present in the sample represented as $32.35,46.38$, 54.03 .

With increased demand for new treatment methods due to development of multiple drug resistant microorganisms, the MB353AgNPs were tested for activity against different microbes. The highest antimicrobial activity was recorded against E.coli (Gram negative) and S. laurentii (Gram positive). However less than 50 percent antibacterial activity was observed against S. aureus and B. subtilis which indicated that these two pathogens were more resistant to silver nanoparticles treatment (Fig. 7). This resistance is probably due to negative surface charge of AgNPs as that negative charged nanoparticles pose resistance against Gram positive bacterium. The antibacterial effect seemed to be independent of the size of the nanoparticles, giving greater importance to the surface charge [28]. Similarly lesser internalization of the AgNPs in gram-positive bacteria because they presented a $-15 \mathrm{mV}$ negative charge on its surface and of MB353AgNps had $-18 \mathrm{mV}$ 
so there is greater possibility that they both repel each other. Previously $S$. aureus has been shown to be more resilient than E. coli in a similar comparison of Gram negative and Gram positive bacterium [29]. The danger of fungal pathogens causing invasive fungal infections has been estimated to be equivalent to tuberculosis [30]. In developing countries like Pakistan there is often inadequate air flow systems in hospitals, and lack of awareness about fungal infections makes the scenario worst [31]. Biogenic silver nanoparticles showed significant antifungal activity against some fungal pathogens with the highest antifungal percentage activity seen against Aspergillus niger $(94 \pm 0.2 \%)$ at $50 \mu \mathrm{g} / \mathrm{ml}$ nanoparticles concentrations. Antifungal activity of silver nanoparticles against Mucor sp. was negligible as compared to the commercial antifungal drug Fluconazole (Fig. 8). Another study has reported the minimum inhibitory concentration of silver nanoparticles against A. flavus, A. nomius and A. parasiticus to be $8 \mu \mathrm{g} / \mathrm{ml}$ [32]. Other work has reported the use of Candida glabrata derived silver nanoparticles as an antimicrobial agent against clinical bacteria (Staphylococcus aureus, E. coli, Pseudomonas aeruginosa, Klebsiella pneumoniae, Salmonella typhimurium and Shigella flexneri) and fungi (Candia albicans, Candida tropicalis, Candida parapsilosis, Candida dubliniensis, Candida krusei and Candida glabrata). The report revealed that silver nanoparticles were good bactericidal at concentrations of 62-250 $\mu \mathrm{g} / \mathrm{ml}$, but fungicidal at higher concentrations $(125-500 \mu \mathrm{g} / \mathrm{ml})$ [33]. The fact that bacterial pathogens were more susceptible than fungal pathogens to silver nanoparticles may be due to the less complex structure of bacterial cells. Similarly, mode of action of silver nanoparticles against bacterial and fungal pathogens was different as they exhibited negative correlation which might be due to their structural complexity. Among bacterial and fungal species, AgNPs mechanistic aspect showed highly positive correlation.

Free radical scavenging activity of silver nanoparticles from Bacillus $s p$. was studied and found that MB353 were not involved in free oxygen radical scavenging activity (Fig. 6). These silver seemed to possess the property of generation of oxygen species rather than scavenging, therefore cytotoxicity of silver nanoparticles was assessed further.

In animals, silver nanoparticles have also been shown to have antitumor activity due to the ability to block the activity of abnormally expressed signaling proteins [34]. In our study, cytotoxic analysis of MB353AgNPs revealed the highest cytotoxicity to be after incubation with $25 \mu \mathrm{g} / \mathrm{ml}$, and showed cell death rates of $88 \pm 1.5 \%$ (fibroblasts), $60 \pm 1.8 \%$ (RD) and $65 \pm 1.4 \%$ (RH30) (Fig. 
9). The greater cell death seen in the control versus healthy cells would limit the use of the silver nanoparticles to situations where the nanoparticles are targeted only to cancerous cells. However, similar work using mammalian cell lines reported that silver nanoparticles showed antitumor potential against breast (MCF-7), hepatocellular (HepG-2) and colon (HCT-116) carcinoma cell lines in a dose-dependent manner with maximum cytotoxicity observed at concentrations of 1.6, 2.3 and $2.2 \mu \mathrm{g} / \mathrm{ml}$, respectively [35]. Our work also demonstrated decreased cell proliferation at higher concentrations of AgNPs using a colony forming assay. Similar findings have been observed using platinum nanoparticles which inhibited colony formation in ovarian teratocarcinoma (PA-1) cells in a dose dependent manner, and resulted in cell cycle arrest [36].

Reactive oxygen species in cells are reponsible for cell cycle arrest and apoptosis by making the mitochnondrial membrane permeable and interrupting the respiratory chain [37]. In this study, elevated ROS generation was observed in RD, RH30 and fibroblast cells when treated with biologically synthesized silver nanoparticles (Fig. 11a), which was indicative of oxidative stress in cells and lack of ATP genetration required for cellular energy. Other studies have also reported silver nanoparticles $(8.7 \mu \mathrm{g} / \mathrm{ml})$ to be inducers of reactive oxygen species in MDA-MB-231 Human breast cancer cells than control after 24 hours of treatment which were the major cause of the inititation of apoptosis [38,39]. Previous studies confirmed that cells use same method of uptake for both anionic and cationic particles but the efficiency of cationic particle uptake was greater than that of anionic particles [40]. Similarly intracellular calcium level also provide insight into mechanism of cell death in fibroblast cells.

\section{Conclusion}

The current study involved the use of indigenous bacterium (Bacillus sp. MB353) to synthesize silver nanoparticles which is low cost and more environmentally friendly than physical or chemical methods. Crystallite size of obtained silevr nanopartciles was approximately $15 \mathrm{~nm}$. The study demonstrated that MB353AgNPs can cause cell death at differet trophic levels i.e. bacteria, fungi and in mammalian cells. Negative surface charge and small size help to combat some bacterial and fungal pathogens therefore could be used as alternative antimicrobial agents. They also induce cytotoxicty by ROS generation so they can also be used in site-directed therapies for cancer treatment. 


\section{References}

[1] Franci, G., Falanga, A., Galdiero, S., Palomba, L., Rai, M., Morelli, G. and Galdiero, M. (2015). Silver nanoparticles as potential antibacterial agents. Molecules., 20(5): 88568874. doi.org/10.3390/molecules/2005/8856

[2] Firdhouse, M. J. and Lalitha, P. (2015). Biosynthesis of silver nanoparticles and its applications. J. Nanotechnol., 2015. doi.org/10.1155/2015/829526

[3] Rai, M., Ingle, A. P., Gade, A. K., Duarte, M. C. T. and Duran, N. (2015). Three Phoma spp synthesized novel silver nanoparticles that possess excellent antimicrobial efficacy. IET nanobiotechnology., 9(5): 280-287. doi.org/10.1049/iet-nbt.2014.0068

[4] Nanda, A. and Saravanan, M. (2009). Biosynthesis of silver nanoparticles from Staphylococcus aureus and its antimicrobial activity against MRSA and MRSE. NanomedNanotechnol., 5(4): 452-456. doi.org/10.1016/j.nano.2009.01.012

[5] Kalimuthu, K., Babu, R. S., Venkataraman, D., Bilal, M. and Gurunathan, S. (2008). Biosynthesis of silver nanocrystals by Bacillus licheniformis. Colloids Surf. B Biointerfaces., 65(1): 150-153. doi.org/10.1016/j.colsurfb.2008.02.018

[6] Ullah, O., Khattak, M., Hasan, F., Raja, N., Hussain, S., Akhtar, N., \& Shah, A. A. (2015). Vancomycin Resistant Enterococcal Infections in Tertiary Care Hospitals of Islamabad and Rawalpindi Pakistan. Pakistan Journal of Zoology, 47(6).

[7] Ullah, A., Qasim, M., Rahman, H., Khan, J., Haroon, M., Muhammad, N. and Muhammad, N. (2016). High frequency of methicillin-resistant Staphylococcus aureus in Peshawar Region of Pakistan. Springerplus, 5(1), 600.

[8] Mao, J. W. (2001). Durable freshness for textiles. AATCC Rev., 1, 28-31.

[9] Meilert, K. T., Laub, D. and Kiwi, J. (2005). Photocatalytic self-cleaning of modified cotton textiles by TiO2 clusters attached by chemical spacers. J Mol Catal A-Chem., 237(1-2): 101-108. doi.org/10.1016/j.molcata.2005.03.040

[10] Banerjee, S., Gopal, J., Muraleedharan, P., Tyagi, A. K. and Raj, B. (2006). Physics and chemistry of photocatalytic titanium dioxide: visualization of bactericidal activity using atomic force microscopy. Curr Sci., 90(10): 1378-1383.

[11] Kaushik, P. and Malik, A. (2009). Fungal dye decolourization: recent advances and future potential. Environ. Int., 35(1): 127-141. doi.org/10.1016/j.envint.2008.05.010 
[12] Lateef, A., Adelere, I. A., Gueguim-Kana, E. B., Asafa, T. B. and Beukes, L. S. (2015). Green synthesis of silver nanoparticles using keratinase obtained from a strain of Bacillus safensis LAU 13. Int. Nano. Let., 5(1): 29-35.

[13] Jo, Y. K., Kim, B. H. and Jung, G. (2009). Antifungal activity of silver ions and nanoparticles on phytopathogenic fungi. Plant Dis., 93(10): 1037-1043. doi.org/10.1094/PDIS-93-10$\underline{1037}$

[14] Khan, N. T. and Jameel, N. (2016). Antifungal activity of silver nanoparticles produced from fungus, Penicillium fellutanum at different pH.J Microb Biochem Technol., 8(5). doi.org/10.4172/1948-5948.1000322

[15] Tang, J., Xiong, L., Wang, S., Wang, J., Liu, L., Li, J. and Xi, T. (2009). Distribution, translocation and accumulation of silver nanoparticles in rats. $J$ Nanosci Nanotechnol., 9(8): 4924-4932. doi.org/10.1166/jnn.2009.1269

[16] Sharma, H. S., Hussain, S., Schlager, J., Ali, S. F. and Sharma, A. (2010). Influence of nanoparticles on blood-brain barrier permeability and brain edema formation in rats. In: Brain edema XIV. Springer, Vienna. pp: 359-364. doi.org/10.1007/978-3-211-98811$\underline{465}$

[17] Shivaji, S., Madhu, S. and Singh, S. (2011). Extracellular synthesis of antibacterial silver nanoparticles using psychrophilic bacteria. Process Biochem., 46(9): 1800-1807. doi.org/10.1016/j.procbio.2011.06.008

[18] Balouiri, M., Sadiki, M. and Ibnsouda, S. K. (2016). Methods for in vitro evaluating antimicrobial activity: A review. $J$ Pharm Anal., 6(2): 71-79. doi.org/10.1016/j.jpha.2015.11.005

[19] Phull, A. R., Abbas, Q., Ali, A., Raza, H., Zia, M. and Haq, I. U. (2016). Antioxidant, cytotoxic and antimicrobial activities of green synthesized silver nanoparticles from crude extract of Bergenia ciliata.Fut. J. Pharma Sci., 2(1): 31-36. doi.org/10.1016/j.fjps.2016.03.001

[20] Elshawy, O. E., Helmy, E. A. and Rashed, L. A. (2016). Preparation, characterization and in vitro evaluation of the antitumor activity of the biologically synthesized silver nanoparticles. Advances in Nanoparticles, 5(02): 149-166.

[21] Akinkunmi, E. O. and Lamikanra, A. (2012). A study of the intestinal carriage of antibiotic resistant Staphylococcus aureus by Nigerian children. Afr Health Sci., 12(3): 381-387. doi.org/10.4314/ahs.v12i3.21

[22] Eliopoulos, G. M. and Gold, H. S. (2001). Vancomycin-resistant enterococci: mechanisms and clinical observations. Clin Infect Dis., 33(2): 210-219. doi.org/10.1086/321815 
[23] Kemung, H. M., Tan, L. T. H., Khan, T. M., Chan, K. G., Pusparajah, P., Goh, B. H. and Lee, L. H. (2018). Streptomyces as a prominent resource of future anti-MRSA drugs. Front Microbiol., 9. doi.org/10.3389/fmicb.2018.02221

[24] Wang, Y. S., Zhou, J., Liang, C., Hong, K., Cheng, X. S. and Wu, Z. G. (2013). ERK5 knock down aggravates detrimental effects of hypothermal stimulation on cardiomyocytes via Bim upregulation. Environ Toxicol Pharmacol., 36(2): 724-731. doi.org/10.1016/j.etap.2013.06.012

[25] Bhainsa, K. C. and D'souza, S. F. (2006). Extracellular biosynthesis of silver nanoparticles using the fungus Aspergillus fumigatus. Colloids Surf B Biointerfaces., 47(2): 160-164. doi.org/10.1016/j.colsurfb.2005.11.026

[26] Gurunathan, S., Kalishwaralal, K., Vaidyanathan, R., Venkataraman, D., Pandian, S. R. K., Muniyandi, J. and Eom, S. H. (2009). Biosynthesis, purification and characterization of silver nanoparticles using Escherichia coli. Colloids Surf B Biointerfaces., 74(1): 328-335. doi.org/10.1016/j.colsurfb.2009.07.048

[27] Gole, A., Dash, C., Ramakrishnan, V., Sainkar, S. R., Mandale, A. B., Rao, M. and Sastry, M. (2001). Pepsin- gold colloid conjugates: preparation, characterization, and enzymatic activity. Langmuir., 17(5): 1674-1679. doi.org/10.1021/la001164w

[28] Salas-Orozco, M., Niño-Martínez, N., Martínez-Castañón, G. A., Méndez, F. T., Jasso, M. E. C. and Ruiz, F. (2019). Mechanisms of resistance to silver nanoparticles in endodontic bacteria: a literature review. J. Nanomat., 2019. doi.org/10.1155/2019/7630316

[29] Kim, J. S., Kuk, E., Yu, K. N., Kim, J. H., Park, S. J., Lee, H. J. and Kim, Y. K. (2007). Antimicrobial effects of silver nanoparticles. Nanomed-Nanotechnol., 3(1): 95-101. doi.org/10.1016/j.nano.2006.12.001

[30] Jabeen, K., Farooqi, J., Mirza, S., Denning, D. and Zafar, A. (2017). Serious fungal infections in Pakistan. Eur. J. Clin. Microbiol. Infect. Dis., 36(6): 949-956. doi.org/10.1007/s10096$\underline{017-2919-6}$

[31] Hanif, F., Ikram, A., Butt, T., Malik, N., Qadir, I. H. and Faiz, U. (2009). Trends of fungal isolates in our set up. Inf. Dis. J Pak., 18: 3-5.

[32] Bocate, K. P., Reis, G. F., de Souza, P. C., Junior, A. G. O., Durán, N., Nakazato, G. and Panagio, L. A. (2019). Antifungal activity of silver nanoparticles and simvastatin against toxigenic species of Aspergillus. Int $J$ Food Microbiol., 291: 79-86. doi.org/10.1016/j.ijfoodmicro.2018.11.012

[33] Jalal, M., Ansari, M., Alzohairy, M., Ali, S., Khan, H., Almatroudi, A. and Raees, K. (2018). Biosynthesis of silver nanoparticles from oropharyngeal Candida glabrata isolates and their antimicrobial activity against clinical strains of bacteria and fungi. Nanomaterials., 8(8): 586. doi.org/10.3390/nano8080586 
[34] Barua, S., Banerjee, P. P., Sadhu, A., Sengupta, A., Chatterjee, S., Sarkar, S. and Karak, N. (2017). Silver nanoparticles as antibacterial and anticancer materials against human breast, cervical and oral cancer cells. J Nanosci Nanotechnol., 17(2): 968-976. doi.org/10.1166/jnn.2017.12636

[35] Gomaa, E. Z. (2017). Antimicrobial, antioxidant and antitumor activities of silver nanoparticles synthesized by Allium cepa extract: a green approach. J Gen Eng and Biotechnol., 15(1): 49-57. doi.org/10.1016/j.jgeb.2016.12.002

[36] Bendale, Y., Bendale, V. and Paul, S. (2017). Evaluation of cytotoxic activity of platinum nanoparticles against normal and cancer cells and its anticancer potential through induction of apoptosis. Integr. Med. Res., 6(2): 141-148. doi.org/10.1016/j.imr.2017.01.006

[37] Park, E. J., Yi, J., Chung, K. H., Ryu, D. Y., Choi, J. and Park, K. (2008). Oxidative stress and apoptosis induced by titanium dioxide nanoparticles in cultured BEAS-2B cells. Toxicol Lett., 180(3): 222-229. doi.org/10.1016/j.toxlet.2008.06.869

[38] Zhu, B., Li, Y., Lin, Z., Zhao, M., Xu, T., Wang, C. and Deng, N. (2016). Silver nanoparticles induce HePG-2 cells apoptosis through ROS-mediated signaling pathways. Nanoscale Res. Lett., 11(1): 198. doi.org/10.1186/s11671-016-1419-4

[39] Gurunathan, S., Han, J. W., Eppakayala, V., Jeyaraj, M. and Kim, J. H. (2013). Cytotoxicity of biologically synthesized silver nanoparticles in MDA-MB-231 human breast cancer cells. Biomed Res Int., 2013. doi.org/10.1155/2013/535796

[40] Fröhlich, E. (2012). The role of surface charge in cellular uptake and cytotoxicity of medical nanoparticles. Int J Nanomedicine., 7: 5577. doi.org/10.2147/IJN.S36111

\section{Conflict of Interest}

All authors declare no conflict of interest. 


\section{List of Figures}

Fig. 1. Growth conditions of the bacterial strain MB353 were assessed to optimize silver nanoparticles synthesis. Physiological conditions were varied (a) Temperature and (b) $\mathrm{pH}$. The culture supernatant of the Bacillus sp. MB353 was monitored with a UV-Vis Spectrophotometr at $420 \mathrm{~nm}$ to quantify silver nanoparticle production. Data expressed as mean $\pm \operatorname{SE}(n=2)$.

Fig. 2. Desirability contours design for AgNPs production from Bacillus sp. MB353 by contour-ft method indicating interactions among $\mathrm{pH}$ and Temperature factors. Predicted values obtained from RSM was $\mathrm{pH} 7$ and Temperature $35^{\circ} \mathrm{C}$.

Fig. 3. UV-visible spectrum of silver nanoparticles synthesized from Bacillus sp. The clear peak at $400 \mathrm{~nm}$ represented synthesis of AgNPs.

Fig. 4. FTIR Analysis of MB353AgNPs with predominant peaks $3419.90 \mathrm{~cm}^{-1}, 2964.69$ 2351.30 and 1620.26 corresponded to the presence of alcohol, phenols, amide groups, carboxylic acids, esters and ethers indicating presence of enzymes/proteins probably nitrate reductases as reducing and stabilizing agents.

Fig. 5. (a) Scanning electron microscope image of cluster of silver nanoparticles. Size of particles range between 49-53nm (they are in aggregated form as shown by yellow circles). Scale bar shows $500 \mathrm{~nm}$. (b) EDX intensity graph of biologically synthesized silver nanoparticle.

Fig. 6. XRD (X-Ray diffraction) analysis of biologically synthesized silver nanoparticles. MB353AgNPs showed amorphous structure.

Fig. 7. DPPH free radical scavenging activity of biosynthesized silver nanoparticles

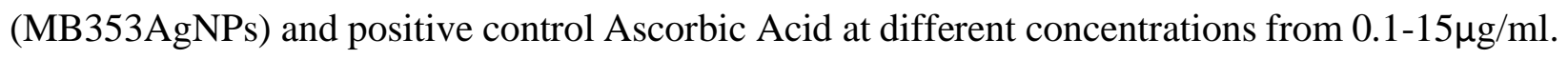
Data expressed as mean \pm , SE, $(n=2)$. Data represents significant variance between different AgNPs concentrations with $p$ value $=0.000671$ i.e. less than 0.05 .

Fig. 8. Biogenic silver nanoparticles induced percentage growth inhibition of selected bacterial pathogens. Selected pathogens were treated with different concentrations of silver nanoparticles, DMSO (+ive control) and Streptomycin (-ive control) $(10 \mu \mathrm{g} / \mathrm{ml})$. Data represents significant variation among different bacterial pathogens as well as at different AgNPs concentrations with $p$ 
value > 0.0001. Highly positive correlation was observed between AgNPs and different bacterial pathogens. Whereas negative/antagonistic against fungal pathogens which suggested that AgNPs exhibited different mechanism of toxicity against bacterial and fungal pathogens.

Fig. 9. Biogenic silver nanoparticles induced percentage growth inhibition of selected fungal

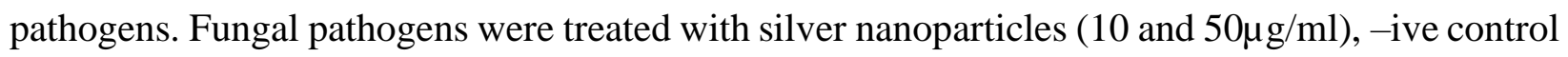
Fluconazole $(10 \mu \mathrm{g} / \mathrm{ml})$. Data expressed as mean \pm , SE, $(\mathrm{n}=2)$. Data represents significant variation among different fungal pathogens as well as with different AgNPs concentrations with $p$ value $>0.0001$. Positive correlation was observed by silver nanoparticles and fungal pathogens. Also MB353AgNPs possessed different mechanism of action against bacterial and fungal pathogens as predicted by negative correlation amongst them.

Fig. 10. Effect of MB353AgNPsnanoparticles on viability of RD, RH30 and Fibroblast cells by crystal violet cytotoxicity assay. Cells treated with different concentrations of silver nanoparticles were left in incubation for 24 hours. Data expressed as mean $\pm \mathrm{SE},(n=3)$.

Fig. 11. Effect of MB353AgNPs on colony forming capacity of exponentially growing RD, RH30 and Fibroblast cells. Cells treated with different concentrations $(0.1,0.5,1$ and $5 \mu \mathrm{g} / \mathrm{ml})$ of silver nanoparticles were allowed to form colonies in fresh medium for 14 days before fixing and staining with Crystal violet. Data expressed as mean $\pm, \mathrm{SE},(\mathrm{n}=3)$.

Fig. 12. ROS overproduction induced by different concentrations of MB353AgNPs at short intervals of time in (a) RD, (b) RH30 and (c) Fibroblast cells. ROS levels were detected by DCF fluorescence intensity. Data expressed as mean $\pm, \mathrm{SE},(\mathrm{n}=3)$.

Fig. 13. Percentage intensity of Intracellular calcium induced by different concentrations of MB353AgNPs at short intervals of time in (a) RD, (b) RH30 and (c) Fibroblast cells. Intracellular $\mathrm{Ca}^{+2}$ levels were detected by Fluo-4- AM fluorescence intensity. Data expressed as mean \pm , Standard error, $(n=3)$. 


\section{List of Table}

Table 1: Analysis of variance (ANOVA) and descriptive statistics for Reduced Linear model 